This is an electronic reprint of the original article. This reprint may differ from the original in pagination and typographic detail.

Author(s): Suhonen, Aku; Nauha, Elisa; Salorinne, Kirsi; Helttunen, Kaisa; Nissinen, Maija

Title: $\quad$ Structural analysis of two foldamer-type oligoamides - the effect of hydrogen bonding on solvate formation, crystal structures and molecular conformation

Year: $\quad 2012$

Version:

Please cite the original version:

Suhonen, A., Nauha, E., Salorinne, K., Helttunen, K., \& Nissinen, M. (2012). Structural analysis of two foldamer-type oligoamides - the effect of hydrogen bonding on solvate formation, crystal structures and molecular conformation. CrystEngComm, 14(21), 7398-7407. https://doi.org/10.1039/c2ce25981h

All material supplied via JYX is protected by copyright and other intellectual property rights, and duplication or sale of all or part of any of the repository collections is not permitted, except that material may be duplicated by you for your research use or educational purposes in electronic or print form. You must obtain permission for any other use. Electronic or print copies may not be offered, whether for sale or otherwise to anyone who is not an authorised user. 


\title{
Structural analysis of two foldamer-type oligoamides - the effect of hydrogen bonding on solvate formation, crystal structures and molecular conformation
}

\author{
Aku Suhonen, Elisa Nauha, Kirsi Salorinne, Kaisa Helttunen and Maija Nissinen* \\ ${ }_{5}$ Received (in $\left.X X X, X X X\right)$ Xth $X X X X X X X X X 20 X X$, Accepted Xth $X X X X X X X X X 20 X X$ \\ DOI: $10.1039 / b 000000 x$
}

The crystal structures and molecular conformations of two foldamer-type oligoamides were analyzed. One polymorphic form and seven solvates were found for $N^{1}, N^{3}$-bis(2-benzamidophenyl)benzene-1,3dicarboxamide (the benzene variant), and two polymorphic forms and six solvates for $N^{2}, N^{6}$-bis(2-

10 benzamidophenyl)pyridine-2,6-dicarboxamide (the pyridine variant). Three crystal structures of the benzene variant and six structures of the pyridine variant were solved using single crystal X-ray diffraction. The crystal structures showed that the different modes of intramolecular hydrogen bonding strongly affect the conformation and folding of the molecules, which is most evidently seen with the strongly folded helical structure of the pyridine variant. NOESY experiments suggest that the

15 intramolecular hydrogen bonding is stable enough to retain a folded or partially folded conformation even in solution.

\section{Introduction}

Hydrogen bonding has been actively studied and discussed for almost a century and its relevance to the organization of 20 molecules cannot be overestimated. ${ }^{1}$ While hydrogen bonds are not as stable and rigid as the covalent bonds, they still are a significant stabilizing force that results in a preferred molecular conformation in the solid state and even in solution. Hydrogen bonds are often used as key elements in crystal engineering ${ }_{25}$ because they are well understood and often predictable. ${ }^{2}$ Their stabilizing effect usually causes the compounds to possess as many hydrogen bonds as possible and their directionality shapes the overall structure further by affecting the crystal packing. Multiple hydrogen bonding has even been observed to cause 30 catalytic properties in some enzymes. ${ }^{3}$ For example, hydrogen bonds can stabilize a negatively charged oxygen atom of the tetrahedral or enolate intermediate formed in many biological reactions, thus decreasing the enthalpic energy cost of the reaction. In these enzymes the hydrogen bond donor

${ }^{a}$ Nanoscience Center, Department of Chemistry, University of Jyväskylä, P.O. BOX 35, 40014 JYU, Finland; Tel: +358 14428 0804; E-mail: maija.nissinen@jyu.fi

$\dagger$ Electronic Supplementary Information (ESI) available: Crystal data and 40 data collection parameters for isomorphous $\mathrm{MeOH}$ and toluene solvates, CIF files of the crystal structures and notes on the crystallographic data. Hydrogen bonding parameters of the structures. Solvent table for crystallizations of 2. Lettering used in the NMR assignment. Assigned ${ }^{1} \mathrm{H}$ and ${ }^{13} \mathrm{C}$ spectra and 2D COSY, HMBC and HMQC spectra of compounds 452 and $3 .{ }^{1} \mathrm{H}$ and ${ }^{13} \mathrm{C}$ spectra of compound $\mathbf{1}$. NOESY spectra of compound 3 in THF- $\mathrm{d}_{8}$ and acetone- $\mathrm{d}_{6}$. TGA-DTA graphs of compound 2 and 3form II $(\mathrm{MeCN})$ slurry of the pyridine variant 3. CCDC reference numbers 885902-885911 See DOI: 10.1039/b000000x/ groups are also preorganized to stabilize the negatively charged 50 intermediate, which in addition decreases the entropic energy cost of the reaction. ${ }^{4}$ Examples of this catalytic effect include serineprotease $^{5}$ and triglyceride hydrolysis by cutinase $\mathrm{e}^{6}$.

The crystal form of a compound, on the other hand, is decided by a multitude of different factors including the properties of the 55 compound, the crystallization conditions, such as temperature and solvent, and by the interactions the compounds are able to form. Therefore, the same compound can crystallize in many different molecular conformations and crystal packing arrangements. This phenomenon is called polymorphism, which has many 60 implications in, for example, industrial applications but which also has academic importance. ${ }^{7}$ Equally important phenomenon in solid state chemistry is the formation of multi-component crystals that are composed of two or more components, i.e. the formation of solvates and co-crystals, which change the physical ${ }_{65}$ and chemical properties of the compounds and affect, for example, their usability in commercial formulations and applications. $^{8}$

Foldamers are an interesting group of synthetic oligomers which imitate some of the properties of biological 70 macromolecules, such as peptides, proteins or DNA. ${ }^{9,10}$ Because of these properties they can be used, for example, as biomimetic catalysts $^{11}$ or receptors, ${ }^{12}$ or as models of protein folding. ${ }^{13}$ The folding properties can be adjusted by designing the oligomers in such a way that weak intramolecular interactions, e.g. hydrogen 75 bonds and $\pi$-stacking, between the key functional groups spontaneously direct the oligomer into a folded conformation.

In order to study the differences in the folding caused by subtle changes in the molecular structure, we designed two potential 


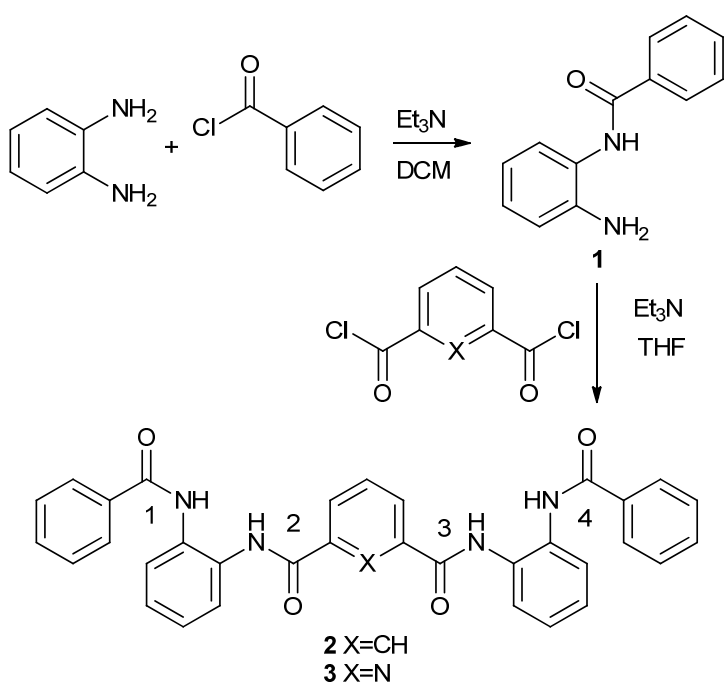

Scheme 1 The reaction scheme for the preparation of oligoamides 2 and 3 showing the amide bond numbering.

foldamers composed of five aromatic rings, which differ in their 5 structure by containing, either a phenyl (2) or a pyridine moiety (3) as the central aromatic ring (Scheme 1). Amide bonds, which connect the aromatic rings of these two molecules and can act both as hydrogen bond acceptors and donors, are a common feature of foldamers because of their structural similarity to the 10 peptide bond in biological molecules composed of amino acids. ${ }^{10,12-16}$ It was anticipated that intramolecular hydrogen bonds could be formed between the two amide groups on both sides of the central aromatic ring, which would ultimately lead to folding like in similar oligoanthranilamides that have previously

15 been shown to fold into intramolecular hydrogen bond stabilized helices both in solution and in the solid state. ${ }^{15,16}$ Aromatic oligoamides composed of pyridine-2,6-dicarboxamide and $N, N$ pyridine-2,6-formamide monomers have been prepared and analyzed by Lehn et al. ${ }^{17,18}$ and Huc et al. ${ }^{19-20}$. Huc et al. ${ }^{21-24}$ 20 have also extensively studied aromatic oligoamide foldamers composed mainly of substituted quinoline monomers and napthpyridine monomers. ${ }^{25}$

In this paper we discuss the effects of weak intra- and intermolecular interactions on the molecular conformation, the ${ }_{25}$ folding properties, the crystal packing and the solvate formation, through a comprehensive solid state structural analysis of two foldamer-type oligoamides. The analysis of these molecules offers insight which can help to design larger peptidomimetic foldamers with predictable secondary structures and properties.

30 Both investigated compounds are capable of adopting a multitude of different conformational polymorphic forms and crystal packing patterns, including a strongly folded proto-helical conformation.

\section{Experimental}

\section{${ }_{35}$ Materials and methods}

All starting materials were commercially available and used as such unless otherwise noted. Analytical grade solvents and Millipore water were used for crystallizations and slurries. NMR spectra were measured with a Bruker Avance DRX 500 40 spectrometer and the chemical shifts were calibrated to the residual proton and carbon resonance of the deuterated solvent. Melting points were measured in open capillaries using a Stuart Scientific SMP3 melting point apparatus and are uncorrected. ESI-TOF mass spectra were measured with a LCT Micromass 45 spectrometer. Elemental analyses were done with a Vario EL III instrument. ATR-IR spectra were measured with a Bruker Tensor 27 spectrometer. TG-DTA measurements were performed with a Perkin Elmer STA600 simultaneous thermal analyzer.

Powder X-ray diffraction data was collected on a PANalytical

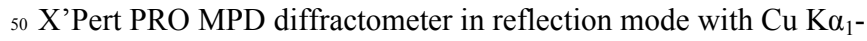
radiation (1.5406 $\AA$ ). A $2 \theta$-angle range of $3-35^{\circ}$ and step time of $75 \mathrm{~s}$ were used with a step resolution of $0.016^{\circ}$. Powder X-ray diffraction samples were pressed to a zero background silicon plate. The figures were drawn with X'Pert Highscore Plus. ${ }^{26}$ ${ }_{55}$ Single crystal X-ray diffraction data was collected with a Bruker Nonius KappaCCD diffractometer at a temperature of $173 \mathrm{~K}$ using a Bruker AXS APEX II CCD-detector and graphitemonochromated $\mathrm{CuK} \alpha$-radiation $(\lambda=1.54178 \AA)$. The structures were solved with direct methods and refined using Fourier 60 techniques with the SHELX-97 software package. ${ }^{27}$ Absorption correction was performed with Denzo-SMN 1997. ${ }^{28}$ All nonhydrogen atoms were refined anisotropically, except for the disordered toluene solvent in structure 3-toluene, and the hydrogen atoms were placed in the idealized positions except for ${ }_{65}$ the $\mathrm{N}-\mathrm{H}$ hydrogen atoms that were found from the electron density map, and included in the structure factor calculations. Details of the crystal data and the refinement are presented in Tables 1 and 2 and in the ESI. The crystal structures were analyzed by calculating packing coefficients ${ }^{29}$ and fingerprint ${ }^{70}$ plots. $^{30}$ The graph set symbols ${ }^{31}$ for hydrogen bonding were assigned and used to compare the bonding between the two molecules and the different crystal structures.

\section{Synthesis}

All syntheses were carried out under $\mathrm{N}_{2}$ atmosphere. The 75 glassware was dried at $120^{\circ} \mathrm{C}$ prior to use. Dichloromethane was dried by distilling it over $\mathrm{CaCl}_{2}$ and stored over Linde type $3 \AA$ molecular sieves under nitrogen gas. Tetrahydrofuran was dried using sodium wire. Compound $\mathbf{1}$ was prepared by a slightly modified literature procedure with an improved yield. ${ }^{32}$

\section{${ }_{80} \mathrm{~N}$-benzoyl-2-aminoaniline $\mathbf{1}^{32}$}

O-phenylenediamine $(8.97 \mathrm{~g} ; 83.1 \mathrm{mmol})$ was dissolved in dry dichloromethane $(350 \mathrm{ml})$. Triethylamine $(3.0 \mathrm{ml} ; 21.6 \mathrm{mmol})$ was added to the solution and the solution was heated to reflux with stirring. Benzoyl chloride (2.16 g; $20.7 \mathrm{mmol})$ dissolved in 85 dry dichloromethane $(200 \mathrm{ml})$ was added dropwise to the solution. The solution was allowed to reflux for two hours. The product was separated by column chromatography with a silica column, using an ethyl acetate-hexane (1:1) mixture as an eluent. Recrystallization from ethyl acetate-hexane afforded the product 90 as a white solid, yield. $3.57 \mathrm{~g}(81 \%)$. mp. $149-151^{\circ} \mathrm{C} ;{ }^{1} \mathrm{H}$ NMR $(\mathrm{ESI} \dagger)\left(500 \mathrm{MHz}, \mathrm{DMSO}-\mathrm{d}_{6}, 30^{\circ} \mathrm{C}\right): \delta=4.87$ (s, 2H; i), $6.60(\mathrm{td}$, $\left.{ }^{3} \mathrm{~J}_{\mathrm{HH}}=1.2 \mathrm{~Hz},{ }^{3} \mathrm{~J}_{\mathrm{HH}}=7.6 \mathrm{~Hz}, 1 \mathrm{H} ; \mathrm{g}\right), 6.79\left(\mathrm{dd},{ }^{3} \mathrm{~J}_{\mathrm{HH}}=1.3 \mathrm{~Hz},{ }^{3} \mathrm{~J}_{\mathrm{HH}}\right.$ $=8.1 \mathrm{~Hz}, 1 \mathrm{H}$; e), $6.97\left(\mathrm{td},{ }^{3} \mathrm{~J}_{\mathrm{HH}}=1.2 \mathrm{~Hz},{ }^{3} \mathrm{~J}_{\mathrm{HH}}=7.6 \mathrm{~Hz}, 1 \mathrm{H}\right.$; f), $7.18\left(\mathrm{~d},{ }^{3} \mathrm{~J}_{\mathrm{HH}}=7.7 \mathrm{~Hz}, 1 \mathrm{H} ; \mathrm{d}\right), 7.51\left(\mathrm{t},{ }^{3} \mathrm{~J}_{\mathrm{HH}}=7.4 \mathrm{~Hz}, 2 \mathrm{H}\right.$; b), 7.55${ }_{95} 7.60(\mathrm{~m}, 1 \mathrm{H} ; \mathrm{a}), 7.98\left(\mathrm{~d},{ }^{3} \mathrm{~J}_{\mathrm{HH}}=7.4 \mathrm{~Hz}, 2 \mathrm{H} ; \mathrm{c}\right), 9.63(\mathrm{~s}, 1 \mathrm{H} ; \mathrm{h})$ ppm; ${ }^{13} \mathrm{C}$ NMR $(\mathrm{ESI} \dagger)\left(126 \mathrm{MHz}, \mathrm{DMSO}-\mathrm{d}_{6}, 30^{\circ} \mathrm{C}\right): \delta=116.1$, $116.2,123.3,126.4,127.6,128.2,131.2,134.6,143.0,165.2$ 
ppm; MS (ESI-TOF) m/z: $235.08\left[\mathrm{M}+\mathrm{Na}^{+}\right]$; Elemental analysis calcd (\%) for $\mathrm{C}_{13} \mathrm{H}_{12} \mathrm{~N}_{2} \mathrm{O}$ : C 73.6, $\mathrm{H}$ 5.7, N 13.2; found $\mathrm{C} 73.8, \mathrm{H}$ 5.6, N 13.3.

\section{General procedure for the preparation of the benzene and ${ }_{5}^{5}$ pyridine variants 2 and 3}

$\mathrm{N}$-benzoyl-2-aminoaniline 1 ( $0.30 \mathrm{~g} ; 1.42 \mathrm{mmol})$ was dissolved in dry tetrahydrofuran $(25 \mathrm{ml})$. Triethylamine $(0.2 \mathrm{ml} ; 1.44 \mathrm{mmol})$ was added and the mixture was stirred at room temperature for an hour. The solution was heated to reflux and isophthaloyl 10 dichloride or 2,6-pyridinedicarbonyl dichloride $(0.71 \mathrm{mmol})$ dissolved in dry tetrahydrofuran $(15 \mathrm{ml})$ was added dropwise to the mixture. The solution was refluxed for two hours.

\section{Benzene variant 2}

Synthesis was done according to the general procedure using 15 isophthaloyl dichloride as a reagent. After reaction the product precipitated from the mixture as a white solid. The precipitate was filtered out and washed with water. Second precipitate was collected from the filtrate after addition of water, and washed with water. Combined precipitates were dried under vacuum. The 20 product was a white solid, which contains appr. 1 molecule of THF for every molecule of $\mathbf{2}$ (according to NMR and TG analysis), yield $80 \%$ mp. $253-254{ }^{\circ} \mathrm{C} ;{ }^{1} \mathrm{H}$ NMR (ESI $\left.\dagger\right)(500 \mathrm{MHz}$, DMSO- $\left._{6}, 30^{\circ} \mathrm{C}\right): \delta=7.29-7.42(\mathrm{~m}, 4 \mathrm{H}, \mathrm{f}$ and $\mathrm{g}), 7.47\left(\mathrm{t},{ }^{3} \mathrm{~J}_{\mathrm{HH}}=\right.$ $7.5 \mathrm{~Hz}, 4 \mathrm{H}$; b), $7.55\left(\mathrm{tt},{ }^{3} \mathrm{~J}_{\mathrm{HH}}=1.4 \mathrm{~Hz},{ }^{3} \mathrm{~J}_{\mathrm{HH}}=7.4 \mathrm{~Hz}, 2 \mathrm{H}\right.$; a), 7.64${ }_{25} 7.73\left(\mathrm{~m}, 5 \mathrm{H}\right.$; d,e and i), 7.93-7.96 (m, 4H; c), $8.13\left(\mathrm{dd},{ }^{3} \mathrm{~J}_{\mathrm{HH}}=1.7\right.$ $\left.\mathrm{Hz},{ }^{3} \mathrm{~J}_{\mathrm{HH}}=7.7 \mathrm{~Hz}, 2 \mathrm{H} ; \mathrm{h}\right), 8.55$ (s, 1H; j), 10.00 (s, 2H; k/1), 10.22 (s, $2 \mathrm{H} ; \mathrm{k} / \mathrm{l}) \mathrm{ppm} ;{ }^{13} \mathrm{C}$ NMR (ESI $\left.\dagger\right)\left(126 \mathrm{MHz}, \mathrm{DMSO}-\mathrm{d}_{6}, 30^{\circ} \mathrm{C}\right): \delta$ $=125.5(\mathrm{f} / \mathrm{g}), 125.6$ (f/g), 125.8 (d,e), 127.0 (j), 127.4 (c), 128.4 (b), 128.8 (i), 130.5 (h), 131.0 (d'), 131.4 (e'), 131.7 (a), 134.2 30 (c'), 134.6 (h'), 164.9 (l'), 165.4 (k') ppm; MS (ESI-TOF) m/z: $577.14 \quad\left[\mathrm{M}+\mathrm{Na}^{+}\right]$; Elemental analysis calcd (\%) for $\mathrm{C}_{34} \mathrm{H}_{26} \mathrm{~N}_{4} \mathrm{O}_{4} \cdot 0.5\left(\mathrm{C}_{4} \mathrm{H}_{8} \mathrm{O}\right): \mathrm{C} 73.2, \mathrm{H}$ 5.1, N 9.5; found $\mathrm{C} 73.3, \mathrm{H}$ $5.1, \mathrm{~N} 9.3$.

\section{Pyridine variant 3}

${ }_{35}$ Synthesis was done according to the general procedure using 2,6pyridinedicarbonyl dichloride as a reagent. After reflux tetrahydrofuran was evaporated leaving a yellow-green precipitate. The precipitate was recrystallized from ethyl acetate as a white solid with a yield of $68 \%$. mp. $251-253^{\circ} \mathrm{C} ;{ }^{1} \mathrm{H}$ NMR $40(\mathrm{ESI} \dagger)\left(500 \mathrm{MHz}, \mathrm{DMSO}-\mathrm{d}_{6}, 30^{\circ} \mathrm{C}\right): \delta=7.21\left(\mathrm{t},{ }^{3} \mathrm{~J}_{\mathrm{HH}}=7.9 \mathrm{~Hz}\right.$, 4H; b) 7.31-7.37 (m, 4H; f) $7.43\left(\mathrm{tt},{ }^{3} \mathrm{~J}_{\mathrm{HH}}=1.2 \mathrm{~Hz},{ }^{3} \mathrm{~J}_{\mathrm{HH}}=7.4 \mathrm{~Hz}\right.$, $2 \mathrm{H}$; a), 7.63-7.71 (m, 4H; d,e) $7.75\left(\mathrm{dd},{ }^{3} \mathrm{~J}_{\mathrm{HH}}=1.2 \mathrm{~Hz},{ }^{3} \mathrm{~J}_{\mathrm{HH}}=7.1\right.$ $\mathrm{Hz}, 4 \mathrm{H} ; \mathrm{c}), 8.27-8.31$ (m, 1H; h), 8.36-8.38 (m, 2H; g), 10.19 (s, $2 \mathrm{H}$; i) 10.99 (s, 2H; j) ppm; ${ }^{13} \mathrm{C}$ NMR (ESI $\left.\dagger\right)(126 \mathrm{MHz}$, DMSO${ }_{45} \mathrm{~d}_{6}, 30^{\circ} \mathrm{C}$ ): $\delta=125.0$ (g), 125.5 (e), 125.6 (f), 125.7 (d), 127.5 (c), 128.0 (b), 130.7 (d'), 131.1 (e'), 131.5 (a), 134.0 (c'), 140.3 (h), 148.2 (g'), 161.2 (j'), 165.9 (i') ppm; MS (ESI-TOF) m/z: 578.16 $\left[\mathrm{M}+\mathrm{Na}^{+}\right]$; Elemental analysis calcd $(\%)$ for $\mathrm{C}_{33} \mathrm{H}_{25} \mathrm{~N}_{5} \mathrm{O}_{4}$ : C 71.3, H 4.5,N 12.6; found C 71.2, H 4.4, N 12.7.

\section{${ }_{50}$ Crystallizations}

The benzene and pyridine variants, 2 and 3, were crystallized in acetone, acetonitrile $(\mathrm{MeCN})$, chloroform, 1,2-dichloroethane (DCE), dichloromethane (DCM), dimethylacetamide (DMA), dimethylformamide (DMF), dimethyl sulfoxide (DMSO), 1,455 dioxane, ethyl acetate (EtOAc), methanol (MeOH), tetrahydrofuran (THF) and toluene. In addition, compound 3 was crystallized from ethanol. Amount of 3-50 mg of compounds 2 and 3 and $0.4-6 \mathrm{ml}$ of solvent were used in the crystallization experiments. Due to the low solubility of compound 2 in most 60 organic solvents, a small drop of DMA, DMF or DMSO (20-40 $\mu \mathrm{l})$ were added to many solutions of 2 , in these cases the results of the crystallizations are referred to as solution mixtures in the text. Heating and stirring were used to help the dissolving process. After the compounds had dissolved, the solutions were ${ }_{65}$ allowed to evaporate at room temperature until crystals formed.

\section{Slurries}

Slurries of the oligoamides 2 and 3 were made by stirring 10-50 $\mathrm{mg}$ of the compound in 2-4 $\mathrm{ml}$ of solvent (MeCN, DCM, EtOAc or THF; in addition, EtOH was used for compound 2 and toluene 70 for compound 3) for two weeks at room temperature. After two weeks the mixtures were allowed to dry in open vessels.

\section{Results and discussion}

\section{Synthesis and NMR}

Compounds $\mathbf{2}$ and $\mathbf{3}$ were synthesized in two steps from acyl 75 halides and substituted anilines using a nucleophilic substitution reaction with good to excellent yields (Scheme 1). In addition to ${ }^{1} \mathrm{H}$ and ${ }^{13} \mathrm{C}$ NMR spectroscopy, compounds $\mathbf{2}$ and $\mathbf{3}$ were characterized using 2D NMR spectroscopic techniques (COSY, HMQC and HMBC; see ESI for details). The conformational 80 properties of $\mathbf{3}$ in solution were studied with NOESY $\uparrow$. The NOESY spectra measured both in acetone- $\mathrm{d}_{6}$ and in THF- $\mathrm{d}_{8}$, showed correlations between the inner amide group peak (amide groups 2 and 3, Scheme 1) and an aromatic hydrogen peak of the outer phenyl rings. This indicates that oligoamide $\mathbf{3}$ is at least ${ }_{85}$ partially folded when dissolved in these solvents. NOESY spectra were not measured for $\mathbf{2}$ because of its poor solubility.

Table 1. Crystal data and collection parameters for the benzene variant (2).

\begin{tabular}{|c|c|c|c|}
\hline & 2-form I & 2-DMSO I & 2-DMSO II \\
\hline Formula & $\mathrm{C}_{34} \mathrm{H}_{26} \mathrm{~N}_{4} \mathrm{O}_{4}$ & $\begin{array}{l}\mathrm{C}_{34} \mathrm{H}_{26} \mathrm{~N}_{4} \mathrm{O}_{4} \cdot \\
\mathrm{C}_{2} \mathrm{H}_{6} \mathrm{OS}\end{array}$ & $\begin{array}{l}\mathrm{C}_{34} \mathrm{H}_{26} \mathrm{~N}_{4} \mathrm{O}_{4} \cdot \\
\mathrm{C}_{2} \mathrm{H}_{6} \mathrm{OS}\end{array}$ \\
\hline $\mathrm{M} / \mathrm{gmol}^{-1}$ & 554.59 & 632.72 & 632.72 \\
\hline Crystal system & monoclinic & triclinic & triclinic \\
\hline Space group & $\mathrm{C} 2 / \mathrm{c}$ & P-1 & P-1 \\
\hline $\mathrm{a} / \AA$ & $39.6877(1)$ & $8.8462(1$ & $8.8810(4)$ \\
\hline $\mathrm{b} / \AA \AA$ & $8.3626(1)$ & $9.6181(1)$ & $14.2224(7)$ \\
\hline $\mathrm{c} / \AA ̊$ & $16.6713(1)$ & $18.7208(1)$ & $14.3149(6)$ \\
\hline$\alpha /^{\circ}$ & 90 & $84.621(1)$ & $114.149(2)$ \\
\hline$\beta /{ }^{\circ}$ & $97.187(1)$ & $85.074(1)$ & $97.447(2)$ \\
\hline$\gamma /{ }^{\mathrm{o}}$ & 90 & $81.720(1)$ & $100.481(4)$ \\
\hline $\mathrm{V} / \AA^{3}$ & $5489.6(1)$ & 1565.1(1) & $1579.8(1)$ \\
\hline Z & 8 & 2 & 2 \\
\hline$\rho_{\text {cald }} / \mathrm{g} \mathrm{cm}^{-3}$ & 1.342 & 1.343 & 1.330 \\
\hline Meas. reflns & 7913 & 6466 & 8159 \\
\hline Indep. reflns & 4653 & 4997 & 5350 \\
\hline $\mathrm{R}_{\text {int }}$ & 0.0813 & 0.0913 & 0.0582 \\
\hline $\mathrm{R}_{1}[\mathrm{I}>2 \sigma(\mathrm{I})]$ & 0.0559 & 0.0677 & 0.0506 \\
\hline $\mathrm{wR}_{2}[\mathrm{I}>2 \sigma(\mathrm{I})]$ & 0.1242 & 0.1413 & 0.1180 \\
\hline GooF & 1.018 & 1.030 & 1.046 \\
\hline
\end{tabular}



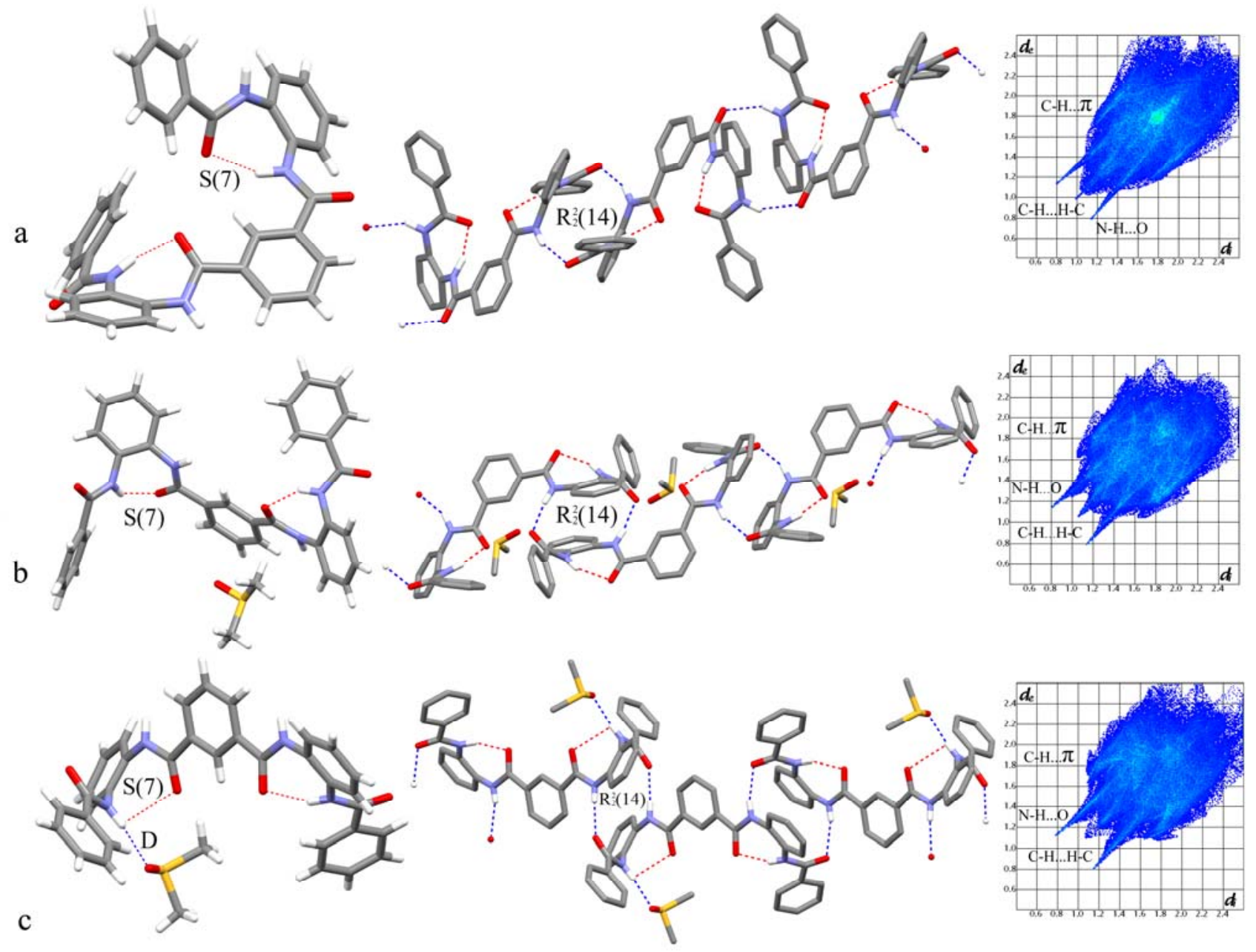

Fig. 1 The molecular conformation (left), the crystal packing (middle) and the fingerprint plot (right) of the benzene variant 2 showing a) 2-form I, b) 2DMSO solvate I and c) 2-DMSO solvate II. Non-hydrogen bonding hydrogen atoms and solvent disorder (2-DMSO I) have been removed for clarity.

\section{Crystal forms of the benzene variant 2}

5 Three single crystal structures were obtained for the oligoamide 2, namely, an unsolvated 2-form I (crystallized from DMF), and two DMSO solvates (2-DMSO I and 2-DMSO II), which were crystallized from DMSO-EtOAc and neat DMSO, respectively (Fig. 1, Table 1). Hydrogen bonding parameters for the structures 10 can be found in the ESI.

Structure 2-form I has two intramolecular hydrogen bonds with an S(7) motif. One of the hydrogen bonds is formed between an inward bent inner $\mathrm{C}=\mathrm{O}$ (Scheme 1, amides 2 and 3) and an outer $\mathrm{N}-\mathrm{H}$ (amides 1 or 4 ), and the other bond between an outer ${ }_{15} \mathrm{C}=\mathrm{O}(1,4)$ and an inner N-H $(2,3)$. These hydrogen bonds cause the molecule to adopt a loosely folded structure (Fig. 1a). Adjacent molecules connect to each other with hydrogen bonds between a carbonyl oxygen and an amide hydrogen (an $R_{2}^{2}(14)$ motif), which are available for the intermolecular hydrogen

20 bonds, forming a chain structure (Fig. 1a). The molecular chains are connected by weak hydrogen bonds, Van der Waals forces and parallel displaced $\pi$-stacking interactions between two of the 1,2-substituted phenyl rings.

The 2-DMSO I solvate has two intramolecular hydrogen bonds ${ }_{25}$ with an S(7) motif similarly to the 2-form I, but both of these bonds are formed between the inner $\mathrm{C}=\mathrm{O}$ groups $(2,3)$ and the outer $\mathrm{N}-\mathrm{H}$ groups $(1,4)$. Therefore, the molecule has a more open conformation than 2-form I (Fig. 1b and Fig. 2). Also, the crystal packing into chains of molecules is similar in comparison to 230 form I, with two hydrogen bonds in an $R_{2}^{2}$ (14) motif (Fig. 1b). Interestingly, although DMSO is a powerful hydrogen bond

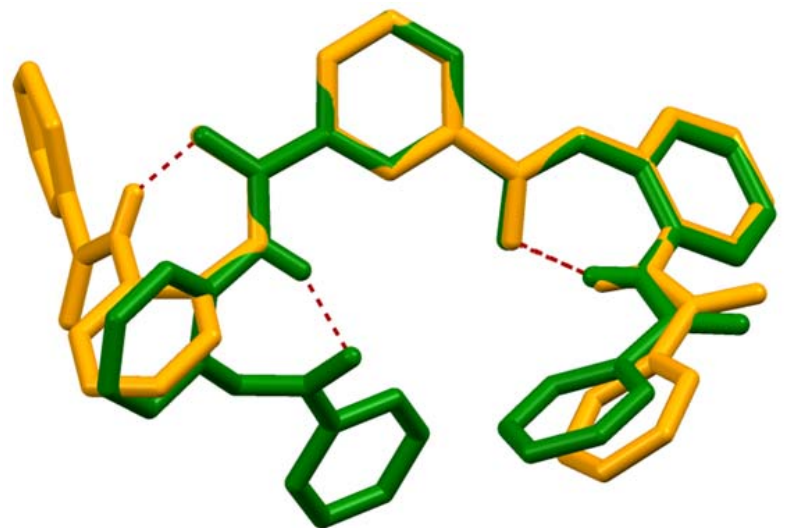

Fig. 2 The overlaid structures of 2-form I (green) and 2-DMSO I solvate (yellow) of the benzene variant 2. Non-contact hydrogen atoms have been removed for clarity. 


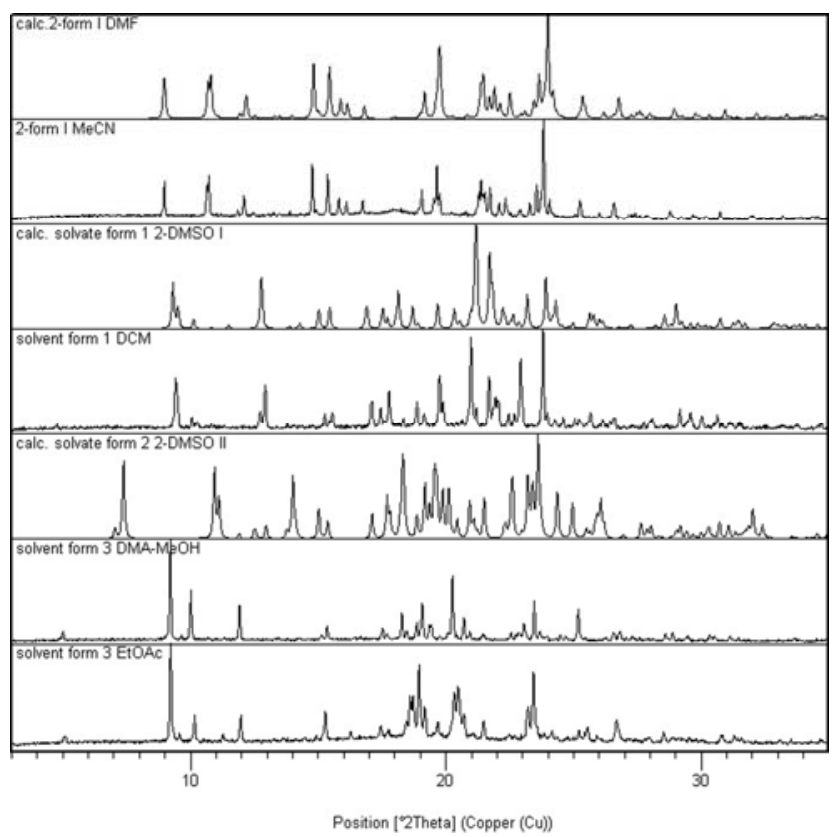

Fig. 3 The measured and the calculated PXRD patterns of the polymorphic and the solvate forms of the benzene variant 2 . Notes on the upper left corners of patterns indicate the solvent or solvents used in the experiment.

acceptor it does not form any significant hydrogen bonds in this structure. It is only connected to other molecules with Van der Waals interactions and weak hydrogen bonds and located in the structural cavities between the chains of molecules.

10 The 2-DMSO II solvate has similar intramolecular hydrogen bonds $\mathrm{S}(7)$ between the inner $\mathrm{C}=\mathrm{O}$ groups $(2,3)$ and the outer $\mathrm{N}$ $\mathrm{H}$ groups $(1,4)$, as does the 2-DMSO I solvate (Fig. 1c). However, unlike in the 2-DMSO I solvate and 2-form I, both of the inner $\mathrm{C}=\mathrm{O}$ groups $(2,3)$ are facing inwards of the molecule 15 and forming a curved conformation instead of an open or a folded one. Again, molecules connect to each other with two hydrogen bonds forming an $R_{2}^{2}(14)$ motif. The unexpected curved molecular conformation, where both of the inner $\mathrm{C}=\mathrm{O}$ groups $(2$, 3) are facing inwards, may in fact be caused by the DMSO that 20 stabilizes the curved structure by forming a hydrogen bond into an amide hydrogen with a D motif. In both of the 2-DMSO I and 2-DMSO II solvates, the closest DMSO molecule to the benzene variant 2 is located near the central benzene ring. This may prevent tighter folding and cause more open molecular 25 conformations.

The reason for the two different DMSO solvates is likely the presence of EtOAc in the crystallization of the 2-DMSO I. Since the DMSO does not form strong hydrogen bonds to the oligoamide in 2-DMSO I, as it does in 2-DMSO II, it is probable 30 that the crystallization starts as an EtOAc solvate and later on the EtOAc molecules are forced out of the crystal and replaced by DMSO.

The packing efficiency of the three forms was compared using fingerprint plots of the structures (Fig. 1). The fingerprint plots 35 are relatively similar because all forms have four hydrogen bonds with the neighbouring molecules of $\mathbf{2}$ and two intramolecular hydrogen bonds. The intermolecular hydrogen bonds are represented by the two long spikes in the fingerprint plot (marked by $\mathrm{N}-\mathrm{H} \cdots \mathrm{O}$ in Fig. 1). The "wings" on the sides of the fingerprint 40 plots represent the $\mathrm{C}-\mathrm{H} \cdots \pi$ interactions and the short spike represents the short $\mathrm{H}-\mathrm{H}$ contacts.

The aromatic interactions play an important role in the crystal packing because the chains of the molecules in all three structures are connected by the interactions between the aromatic hydrogen 45 atoms of a molecule in one chain and the aromatic carbons in the other chains, along with the weak hydrogen bonds between the carbonyl oxygens and the aromatic hydrogens. The packing coefficients suggest that the 2-DMSO I solvate is the best packed of the three, but the differences are relatively small (2-form I: ${ }_{50} 0.722$, 2-DMSO I: 0.724 and 2-DMSO II: 0.717 ). This suggests that the efficiency of the different packing patterns is almost equal.

In addition to the single crystal studies, powder X-ray diffraction revealed five crystal forms for the oligoamide 2 . ${ }_{55}$ Crystallization of 2 from DCE, EtOH, MeCN and $\mathrm{MeOH}$ and slurries from $\mathrm{MeCN}$ and $\mathrm{EtOH}$ were identified to produce 2-form I by PXRD (Fig. 3). However, crystals suitable for single crystal $\mathrm{X}$-ray diffraction were not obtained. Crystallizations from EtOAc-DMSO, DCM and THF, and slurries from DCM and THF ${ }_{60}$ produced solvates, which are isomorphous with the structure 2DMSO-I based on their PXRD patterns (Fig. 3). In addition, crystals obtained from crystallization from EtOAc, and crystallizations from solvent mixtures of DMF with chloroform, EtOAc, THF and toluene; from solvent mixtures of DMA with ${ }_{65} \mathrm{EtOH}, \mathrm{MeOH}$ and $\mathrm{MeCN}$; and a slurry from EtOAc were assigned into third isomorphous group of oligoamide 2 solvates based on their PXRD patterns (ESI $\dagger$ ). PXRD patterns of DMF and DMA with other solvents were so similar that most likely the crystals from these experiments are similar to the 2-DMSO I 70 solvate. Meaning that they are either DMF or DMA solvates, which have a different structure than if they would have been formed from crystallizations with just DMA or DMF. TGanalysis performed on the MeCN, EtOAc and THF slurries support the results of the PXRD studies. Slurries other than ${ }_{75} \mathrm{MeCN}$ are solvates. The samples were also analyzed using ATRIR-spectroscopy, but the different forms could not be unambiguously identified likely due to the simultaneous presence of the different crystalline forms and the solvents in the samples.

The reoccurring chain structure observed in the crystal 80 structures of $\mathbf{2}$ may explain both the low solubility of the compound, as well as, the strong tendency of $\mathbf{2}$ to form isomorphous solvates readily with many different solvents. Solvent layers form between and around the chains.

\section{Crystal forms of the pyridine variant 3}

${ }_{85}$ Seven single crystal structures were obtained for the pyridine variant 3 (Table 2, Fig. 4, ESI $\dagger$ ). One of the structures is a loosely packed unsolvated 3-form I and the six others are solvates: isomorphous 3-MeOH and 3-EtOH solvates, isomorphous 3EtOAc and 3-toluene solvates, 3-DMF solvate and 3-DMSO 90 solvate. Hydrogen bonding parameters for the structures can be found in the ESI.

The single crystal structure of 3-form I was obtained from the slow evaporation crystallizations from EtOAc and $\mathrm{MeCN}$ solutions. The 3-form I has three intramolecular hydrogen bonds 95 that are all formed between the same outer $\mathrm{C}=\mathrm{O}$ groups $(1$ or 4$)$ 

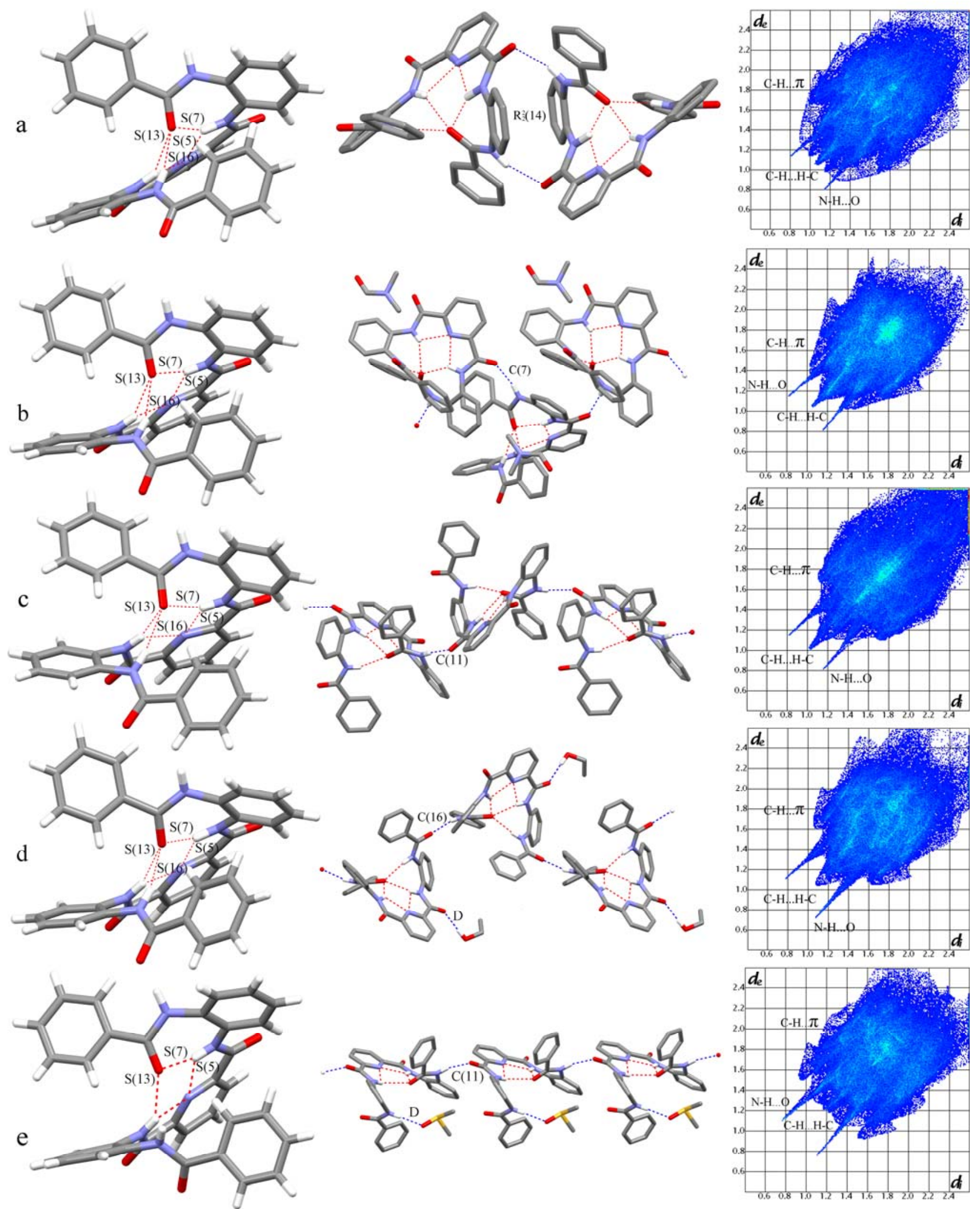

Fig. 4 The molecular conformation (left), packing (middle) and fingerprint plot (right) of the pyridine variant 3 showing a) 3-form I, b) the 3-DMF solvate, c) the 3-EtOAc solvate, d) the 3-EtOH solvate and e) the 3-DMSO solvate. Non-contact hydrogen atoms, form I benzene ring disorder and DMF solvate solvent disorder removed for clarity. 
Table 2. Crystal data and collection parameters for the pyridine variant (3).

\begin{tabular}{|c|c|c|c|c|c|}
\hline & 3-form I & 3-DMF & 3-EtOAc ${ }^{\mathrm{a}}$ & $3-\mathrm{EtOH}^{\mathrm{a}}$ & 3-DMSO \\
\hline Formula & $\mathrm{C}_{33} \mathrm{H}_{25} \mathrm{~N}_{5} \mathrm{O}_{4}$ & $\mathrm{C}_{33} \mathrm{H}_{25} \mathrm{~N}_{5} \mathrm{O}_{4} \cdot \mathrm{C}_{3} \mathrm{H}_{7} \mathrm{NO}$ & $\mathrm{C}_{33} \mathrm{H}_{25} \mathrm{~N}_{5} \mathrm{O}_{4} \cdot 0.5 \mathrm{C}_{4} \mathrm{H}_{8} \mathrm{O}_{2}$ & $\mathrm{C}_{33} \mathrm{H}_{25} \mathrm{~N}_{5} \mathrm{O}_{4} \cdot \mathrm{C}_{2} \mathrm{H}_{6} \mathrm{O}$ & $\mathrm{C}_{33} \mathrm{H}_{25} \mathrm{~N}_{5} \mathrm{O}_{4} \cdot \mathrm{C}_{2} \mathrm{H}_{6} \mathrm{OS}$ \\
\hline $\mathrm{M} / \mathrm{gmol}^{-1}$ & 555.58 & 628,68 & 599.63 & 601.65 & 633.71 \\
\hline Crystal system & triclinic & monoclinic & monoclinic & monoclinic & monoclinic \\
\hline Space group & P-1 & $\mathrm{P} 2_{1} / \mathrm{c}$ & $\mathrm{P} 2{ }_{1} / \mathrm{c}$ & $\mathrm{P} 2{ }_{1} / \mathrm{c}$ & $\mathrm{P} 2{ }_{1} / \mathrm{c}$ \\
\hline $\mathrm{a} / \AA$ & $10.5379(7)$ & $14.0456(7)$ & $12.4871(5)$ & $13.2559(4)$ & $9.7193(5)$ \\
\hline $\mathrm{b} / \AA ̊$ & $11.5380(7)$ & $19.2718(8)$ & $16.7357(7)$ & $16.6185(6)$ & $18.6564(8)$ \\
\hline $\mathrm{c} / \AA$ & $12.1818(7)$ & $11.4694(5)$ & $14.7175(7)$ & $16.8199(6)$ & $17.5185(8)$ \\
\hline$\alpha /^{\circ}$ & $78.559(3)$ & 90 & 90 & 90 & 90 \\
\hline$\beta /{ }^{o}$ & $74.708(3)$ & $94.781(2)$ & $90.296(2)$ & $126.354(2)$ & $92.741(2)$ \\
\hline$\gamma /{ }^{\circ}$ & $77.753(4)$ & 90 & 90 & 90 & 90 \\
\hline $\mathrm{V} / \AA^{3}$ & $1380.2(2)$ & $3093.8(2)$ & $3070.1(2)$ & 2984.1(2) & $3172.9(3)$ \\
\hline Z & 2 & 4 & 4 & 4 & 4 \\
\hline$\rho_{\text {calc }} / \mathrm{g} \mathrm{cm}^{-3}$ & 1.337 & 1.350 & 1.202 & 1.339 & 1.327 \\
\hline Meas. reflns & 6344 & 8937 & 8295 & 8338 & 9190 \\
\hline Indep. reflns & 4582 & 5250 & 4991 & 5123 & 5306 \\
\hline $\mathrm{R}_{\text {int }}$ & 0.0826 & 0.0725 & 0.0529 & 0.0533 & 0.0700 \\
\hline $\mathrm{R}_{1}[\mathrm{I}>2 \sigma(\mathrm{I})]$ & 0.0603 & 0.0575 & 0.0535 & 0.0551 & 0.0527 \\
\hline $\mathrm{wR}_{2}[\mathrm{I}>2 \sigma(\mathrm{I})]$ & 0.1393 & 0.1253 & 0.1242 & 0.1231 & 0.1109 \\
\hline GooF & 1.041 & 1.047 & 0.981 & 1.028 & 1.022 \\
\hline
\end{tabular}

${ }^{a}$ Information on the isomorphous solvate structures is presented in ESI.

and three of the N-H groups with $\mathrm{S}(7), \mathrm{S}(13)$ and $\mathrm{S}(16)$ motifs (Fig. 4a). This causes the molecule to adopt a strongly folded 5 structure. There are also two hydrogen bonds between the nitrogen of the pyridine ring and the inner N-H $(2,3)$ hydrogen atoms with an $\mathrm{S}(5)$ motif that stabilize the folded conformation. The crystal packing of 3-form I is composed of molecule pairs held together by two hydrogen bonds between the carbonyl and 10 the amide groups with an $R_{2}^{2}(14)$ motif (Fig. 4a). There are also indigenous $33 \AA^{3}$ voids in the structure. The voids found in the structure are either evidence of inefficient packing, or an indication of a possible solvate formation before the formation of 3-form I.

15 The 3-DMF solvate structure has the same five intramolecular hydrogen bonds that cause a similar strongly folded structure as in 3-form I (Fig. 4b). The molecules pack into chains connected via $\mathrm{C}=\mathrm{O} \cdots \mathrm{N}-\mathrm{H}$ hydrogen bonds with a $\mathrm{C}(7)$ motif. The $\mathrm{DMF}$ solvent does not form any medium or strong hydrogen bonds with 20 the other molecules. PXRD studies also indicate that the DMF solvate of the pyridine variant $\mathbf{3}$ has five isomorphous solvates (acetone, 1,4-dioxane, DMA, pyridine and THF), but only DMF produced crystals suitable for single crystal XRD measurement.

The ethyl acetate solvate was at first discovered during the 25 recrystallization phase of the synthesis when the crude product was dissolved in hot EtOAc and cooled in a refrigerator. The structure has one EtOAc molecule for every two molecules of the pyridine variant 3 . The molecular conformation is again similar to the 3-form I and the DMF solvate, but the packing is slightly 30 different. The molecules form a chain with a C(11) motif (Fig. $4 c)$. The ethyl acetate solvate has an isomorphous toluene solvate formed from evaporation crystallization from toluene.

The isomorphous solvates $3-\mathrm{MeOH}$ and $3-\mathrm{EtOH}$ have a similar molecular conformation as the 3-DMF, 3-EtOAc and 3-toluene 35 solvates and 3 -form I. The molecules pack into chains of molecules with a $\mathrm{C}(16)$ motif (Fig. 4d). The solvent is hydrogen bonded to one of the inner $\mathrm{C}=\mathrm{O}$ groups $(2,3)$ with a $\mathrm{D}$ motif. The $3-\mathrm{MeOH}$ and 3-EtOH solvates have identical structural features apart from solvent disorder, which is observed with the smaller $40 \mathrm{MeOH}$, but not with EtOH.
The 3-DMSO solvate crystallized overnight from a sample where the pyridine variant $\mathbf{3}$ was dissolved in DMSO by heating the sample. It has a slightly different molecular conformation than the other forms crystallized from the pyridine variant 3 (Fig. $\left.{ }_{45} 4 \mathrm{e}\right)$. The solvate has two S(5) hydrogen bonds, one S(7) and one $\mathrm{S}(13)$ hydrogen bond, but the $\mathrm{S}(16)$ hydrogen bond is not formed. Instead a hydrogen bond is formed with the DMSO molecule with a D motif (Fig. 4e). The molecules of the pyridine variant 3 form chains with a $C(11)$ motif, but the conformation of the 50 molecules in the chain differs from the $\mathrm{C}(11)$ motif chain formed in the 3-EtOAc and 3-toluene solvates. The chain of molecules formed by the 3-DMSO solvate is more consistent in shape than the other $\mathrm{C}(11)$ chain (Fig. 4c and 4e).

Nothing certain can be said about the possible hydrogen ${ }_{55}$ bonding between the pyridine variant $\mathbf{3}$ and EtOAc because the solvent molecule had to be removed from the final refinement of the 3-EtOAc solvate structure by SQUEEZE due to severe disorder. Most likely the 3-EtOAc solvate does not form any hydrogen bonds because it has no hydrogen bond donor groups 60 and the molecules of the pyridine variant $\mathbf{3}$ are in a molecular conformation where only one hydrogen donor group is facing outside the molecule. In addition, this same donor group is already forming a hydrogen bond with the neighboring pyridine variant 3 molecule (Fig. 4c). Also, based on the isomorphous 365 toluene solvate, which possesses the same molecular ratio, conformation and structure as the 3-EtOAc solvate, it seems that the role of the solvent is again merely to fill the interstice between the chains. The same applies to the 3-DMF solvate. In the 3-DMSO solvate the molecular conformation is changed and 70 a hydrogen bond is formed between the solvate and the pyridine variant 3 molecule (Fig. 4e). This is most likely due to the fast crystallization process and the powerful hydrogen bond forming tendencies of DMSO.

As the molecular conformations in all the crystal structures, 75 aside from the DMSO solvate, are so similar, the differences between these structures clearly stem from the differences in the crystal packing and the hydrogen bonding. The packing coefficient of the 3-DMF solvate is the highest $(\mathrm{C}(\mathrm{k})=0.735)$ 


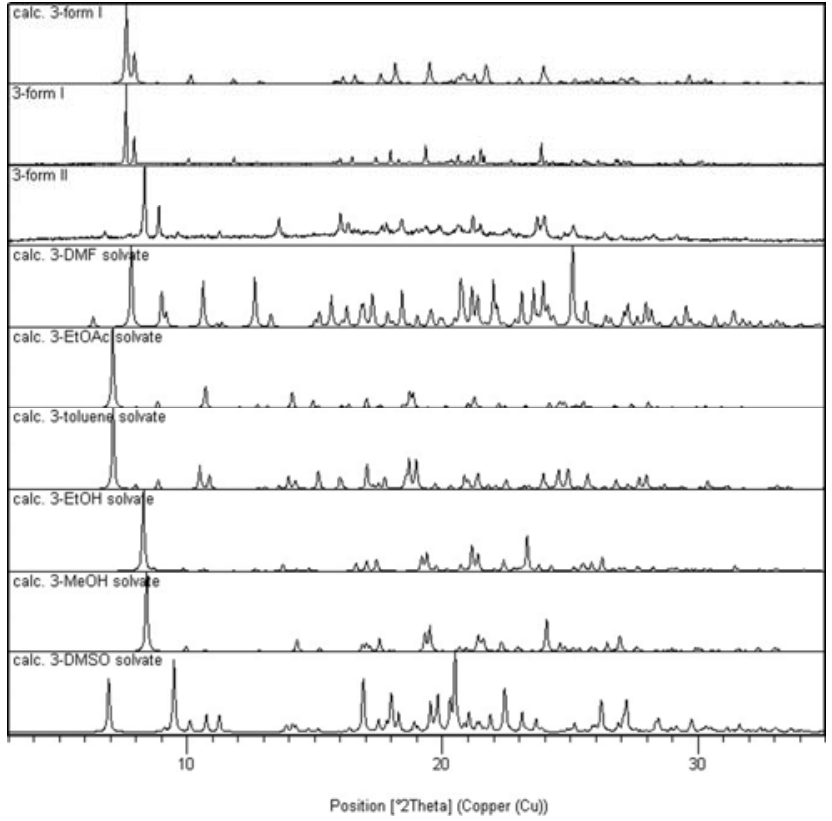

Fig. 5 The measured and the calculated PXRD patterns of the polymorphic and the solvate forms of the pyridine variant 3 .

followed by the $3-\mathrm{MeOH}$ and $3-\mathrm{EtOH}$ solvates $(0.731$ and 0.732 , 5 respectively), 3-form I (0.712), DMSO solvate (0.709) and the 3toluene and 3-EtOAc solvates (0.701 and 0.699). The differences in the stability and the packing efficiency between 3-form I and the 3-EtOAc solvate predicted by their packing coefficients are confirmed by the experimental observations. The 3-EtOAc 10 solvate only forms when a fast change in the temperature of the solvent causes a fast crystallization. When the temperature changes more slowly, the crystallization from EtOAc produces 3form I. The lower packing efficiency of the 3-DMSO solvate indicated by its packing coefficient is also most likely the result 15 of its fast crystallization. The difference between the packing efficiency of 3-form I and the 3-EtOH, 3-MeOH and 3-DMF solvates is also understandable because the crystal structures show that 3-form I has voids in its structure that are not found in these solvate structures.

20 The fingerprint plots of the structures also demonstrate the differences (Fig. 4). Compared to 3-form I, the 3-DMSO,3$\mathrm{MeOH}$ and 3-EtOH solvates have an extra intermolecular hydrogen bond to the solvent molecule. The fingerprint plots of the solvates also have clearly defined "wings" caused by the C${ }_{25} \mathrm{H} \cdots \pi$ interactions that connect the different molecular chains. While these interactions are relatively weak alone, together they can have a significant effect on the stability of the crystal structure. The 3-form I has a well defined center spike caused by the short $\mathrm{C}-\mathrm{H} \cdots \mathrm{H}-\mathrm{C}$ distances between the molecular pairs. 30 These short distances between the aromatic hydrogen atoms can make the structure more unstable, but at the same time are too weak to affect the overall molecular conformation caused by the intramolecular hydrogen bonds, or break the hydrogen bonds that form the molecular pairs. The molecular pairs and the chains of 35 molecules formed in the structures are connected by weak hydrogen bonds, Van der Waals interactions and parallel displaced and T-shaped $\pi$-stacking.

In addition to the single crystal structures, the pyridine variant 3 has also at least one other polymorphic form (3-form II) that
40 was found using PXRD, TGA-DTA and ATR-IR measurements (Fig. 5, Fig. 6). The IR spectra of 3-form II is easily distinguishable from the spectra of 3-form I by its carbonyl peak at $1675 \mathrm{~cm}^{-1}$. Unlike 3 -form II, the carbonyl peak of 3-form I is split between a stronger and a weaker peak, at $1687 \mathrm{~cm}^{-1}$ and $451673 \mathrm{~cm}^{-1}$. The splitting is caused by one carbonyl oxygen that is more strongly hydrogen bonded than the other three, whereas the single carbonyl peak of 3-form II indicates that all of its carbonyl groups are in a more similar environment. 3-form II is formed from evaporation crystallizations from DCM and MeCN. TGA50 DTA measurement confirmed that the 3-form II is indeed a polymorph and not a solvate (ESI $\dagger)$.

\section{Structural comparison of the compounds}

The differences in the molecular conformations and the crystal structures of the benzene and pyridine variant are significant 55 despite of the very small difference in their molecular structure (Fig. 7). The exchange of the central phenyl ring to a pyridine ring causes a drastic change from a relatively loose molecular conformation to a more folded structure with a unique hydrogen bond pattern of five intramolecular hydrogen bonds, three of 60 which are to the same carbonyl group. The benzene variant 2, on the other hand, has only two intramolecular hydrogen bonds. The hydrogen bonds of the benzene variant $\mathbf{2}$ are more evenly distributed resulting in a structure that has no unused hydrogen bond donors or acceptors. Whereas, the pyridine variant $\mathbf{3}$, ${ }_{65}$ because of its many hydrogen bonds to single carbonyl oxygen, has two unused strong hydrogen bond acceptors (Fig. 7). Because of the different intramolecular hydrogen bond patterns the chains of molecules of the benzene variant 2 are held together by two intermolecular $\mathrm{H}$-bonds for each molecule and the chains of the 70 pyridine variant 3 only by one.

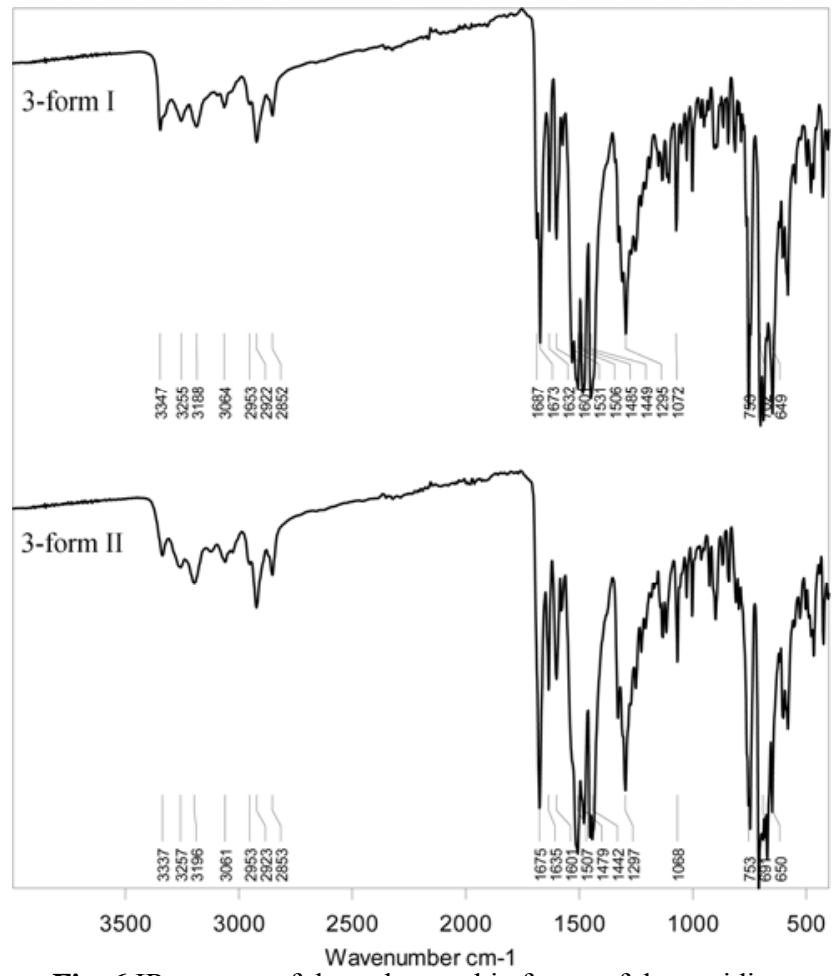

Fig. 6 IR-spectra of the polymorphic forms of the pyridine variant 3. 


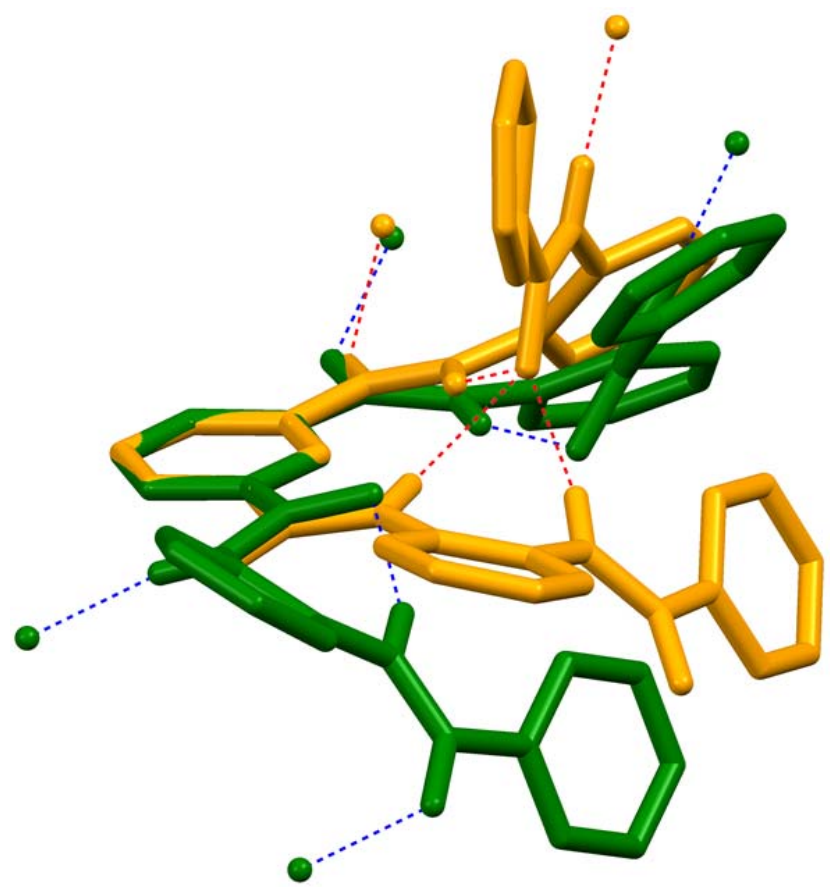

Fig. 7 Overlaid structures of the benzene variant 2 2-form I (green) and the pyridine variant 3 3-form I (yellow). The hydrogen bonds of the benzene variant are shown in blue and the bonds of the pyridine variant 5 are shown in red. Non-contact hydrogen atoms have been removed for clarity.

\section{Conclusions}

Two new potential oligoamide foldamers, the benzene and the pyridine variants, were prepared and their solid state structures 10 were analyzed using various crystallographic and spectroscopic methods. For the benzene variant 2 four crystal forms, either polymorphs or solvates, were found and three structures were solved using single crystal X-ray diffraction. All the crystal structures of the benzene variant 2 consist of molecular chains

15 formed by two intermolecular hydrogen bonds, where all the hydrogen bond acceptor and donor groups in the molecule are in efficient use.

For the pyridine variant $\mathbf{3}$ eight different polymorphs or solvates were found and the single crystal structures of seven of 20 these were solved. Six of the forms are solvates: the 3-DMSO solvate and the isomorphous $3-\mathrm{MeOH}$ and $3-\mathrm{EtOH}$ solvates, in which the solvent forms a hydrogen bond with the pyridine variant 3; the isomorphous 3-EtOAc and 3-toluene solvates; and the 3-DMF solvate, in which the solvent does not hydrogen bond 25 with the pyridine variant, but interacts with compound 3 molecules by Van der Waals interactions and possibly weak hydrogen bonds.

The molecular conformation of the pyridine variant 3 in all crystal structures (except in the 3-DMSO solvate) consists of a 30 unique hydrogen bonding pattern, where three of the N-H groups of each molecule form hydrogen bonds to the same carbonyl group. This leaves two unused hydrogen bond acceptors, which makes the pyridine variant $\mathbf{3}$ a good candidate for further cocrystallization experiments with compounds that have strong 35 hydrogen bond donor groups. In addition, this type of multiple hydrogen bonding to a single carbonyl oxygen also indicates a possible catalytic effect on the carbonyl group of the compound.

\section{Acknowledgements}

M.Sc. Jussi Ollikka, B.Sc Hélène Campos Barbosa and B.Sc. 40 Miia-Elina Puranen are thanked for the help with the synthesis and crystallization. We would also like to thank Spec. Lab. Technician Mirja Lahtiperä for measuring the ESI-TOF mass spectra, Spec. Lab. Technician Elina Hautakangas for the elemental analysis, Spec. Lab. Technician Reijo Kauppinen for ${ }_{45}$ measuring the ${ }^{1} \mathrm{H},{ }^{13} \mathrm{C}$, COSY, HMBC and HMQC NMR spectra and Spec. Lab. Technician Esa Haapaniemi for measuring the NOESY NMR spectra.

\section{Notes and references}

1. E. Arunan, G.R. Desiraju, R.A. Klein, J. Sadlej, S. Scheiner, I. Alkorta, D.C. Clary, R.H. Crabtree, J.J. Dannenberg, P. Hobza, H.G Kjaergaard, A.C. Legon, Benedetta Mennucci and D.J. Nesbitt, Pure Appl. Chem., 2011, 83, 1637.

2. C.B. Aakeröy and N. Schultheiss, in Making Crystals by Design, ed. D. Braga and F. Grepioni, WILEY-VCH Verlag GmbH \& Co. ${ }_{55}$ KGaA, Weinheim, Germany, 2007, pp. 209.

3. A.R. Fersht, J.-P. Shi, J. Knill-Jones, D.M. Lowe, A.J. Wilkinson, D.M. Blow, P. Brick, P. Carter, M.M.Y. Waye and G. Winter, Nature, 1985, 314, 235.

4. P.M. Pihko, S. Rapakko and R.K. Wierenga, in Hydrogen Bonding in 60 Organic Synthesis, ed. P.M. Pihko, WILEY-VCH Verlag GmbH \& Co. KGaA, Weinheim, Germany, 2009, pp. 43

5. C.N. Fuhrmann, M.D. Daugherty and D.A. Agard, J. Am. Chem. Soc., 2006, 128, 9086.

6. C. Martinez, A. Nicolas, H. van Tilbeurgh, M.-P. Egloff, C. Cudrey, 65 R. Verger and C. Cambillau, Biochemistry, 1994, 33, 83.

7. J. Bernstein, Polymorphism in Molecular Crystals, Oxford University Press, United States, 2002.

8. U.J. Griesser, in Polymorphism in the Pharmaceutical Industry, ed. R. Hilfiker, WILEY-VCH Verlag GmbH \& Co. KGaA, Weinheim,

70 Germany, 2006, pp. 211.

9. S.H. Gellman, Acc. Chem. Res., 1998, 31, 173.

10. D.J. Hill, M.J. Mio, R.B. Prince, T.S. Hughes and J.S. Moore, Chem. Rev., 2001, 101, 3893.

11. J. Zhu, R.D. Barra, H. Zeng, E. Skrzypczak-Jankun, X.C. Zeng and B. Gong, J. Am. Chem. Soc., 2000, 122, 4219.

12. R.R. Araghi and B. Koksch, ChemmComm, 2011, 47, 3544.

13. P. Claudon, A. Violette, K. Lamour, M. Decossas, S. Fournel, B. Heurtault, J. Godet, Y. Mély, B. Jamart-Grégoire, M.-C. AverlantPetit, J.-P. Briand, G. Duportail, H. Monteil and G. Guichard, Angew. Chem., Int. Ed., 2010, 49, 333.

14. C. Baldauf, R. Günther and H.-J. Hofmann, J. Org. Chem., 2006, 71, 1200

15. Y. Hamuro, S.J. Geib and A.D. Hamilton, J. Am. Chem. Soc., 1996, 118, 7529 .

85 16. Y. Hamuro, S.J. Geib and A.D. Hamilton, J. Am. Chem. Soc., 1997, 119, 10587.

17. V. Berl, I. Huc, R.G. Khoury and J.-M. Lehn, Chem. Eur. J., 2001, 7, 2798 .

18. V. Berl, I. Huc, R.G. Khoury and J.-M. Lehn, Chem. Eur. J., 2001, 7, 2810.

19. I. Huc, V. Maurizot, H. Gornitzka and J.-M. Léger, Chem. Commun. 2002, 578 .

20. B. Baptiste, J. Zhu, D. Haldar, B. Kauffmann, J.-M. Léger and I. Huc, Chem. Asian J., 2010, 5, 1364

95 21. H. Jiang, J.-M. Léger and I. Huc, J. Am. Chem. Soc.. 2003, 125, 3448.

22. E.R. Gillies, C. Dolain, J.-M. Léger and I. Huc, J. Org. Chem., 2006, 71, 7931.

23. N. Delsuc, J.-M. Léger, S. Massip and I. Huc, Angew. Chem. Int. Ed., 2007, 46, 214. 
24. D. Sánchez-Garcia, B. Kauffmann, T. Kawanami, H. Ihara, M. Takafuji, M.-H. Delville and I. Huc, J. Am. Chem. Soc., 2009, 131, 8642.

25. Y. Ferrand, A.M. Kendhale, J. Garric, B. Kauffman and I. Huc, Angew. Chem. Int. Ed., 2010, 49, 1778.

26. PANalytical B.V., 2006, 2.2b.

27. G.M. Sheldrick, Acta Crystallogr. A., 2008, 64, 112.

28. Z. Otwinowski, D. Borek, W. Majewski ja W. Minor, Acta Crystallogr. A., 2003, 59, 228.

10 29. A.I. Kitaĭgorodskiı̌, Organic Chemical Crystallography, Consultants Bureau, New York, 1961.

30. M.A. Spackman and J.J. McKinnon, CrystEngComm, 2002, 4, 378.

31. M.C. Etter and J.C. MacDonald, Acta Crystallogr., Sect. B: Struct. Sci., 1990, 46, 256; J. Bernstein, R. E. Davis, L. Shimoni and N.-L. 15 Chung, Angew. Chem., Int. Ed., 1995, 34, 1555.

32. X. Bao and Y. Zhou, Sensors and Actuators B: Chemical, 2010, 147, 434. 